\title{
Pollen reveals the plant world of the past
}

\section{Andrea Miebach}

Achoo! Everyone knows it: it's getting warm outside, plants are flowering, and allergy sufferers are having a hard time. Pollen! It's annoying, but studying pollen grains unveils their beauty and utility. By having a look through the microscope, we can discover how diverse and pretty they are. Most importantly, pollen helps us understand past vegetation and the factors that control it, like climate change. How? Let's explore where we find pollen, what pollen grains look like, and what we can learn from them. There is so much to discover about these microscopic structures...

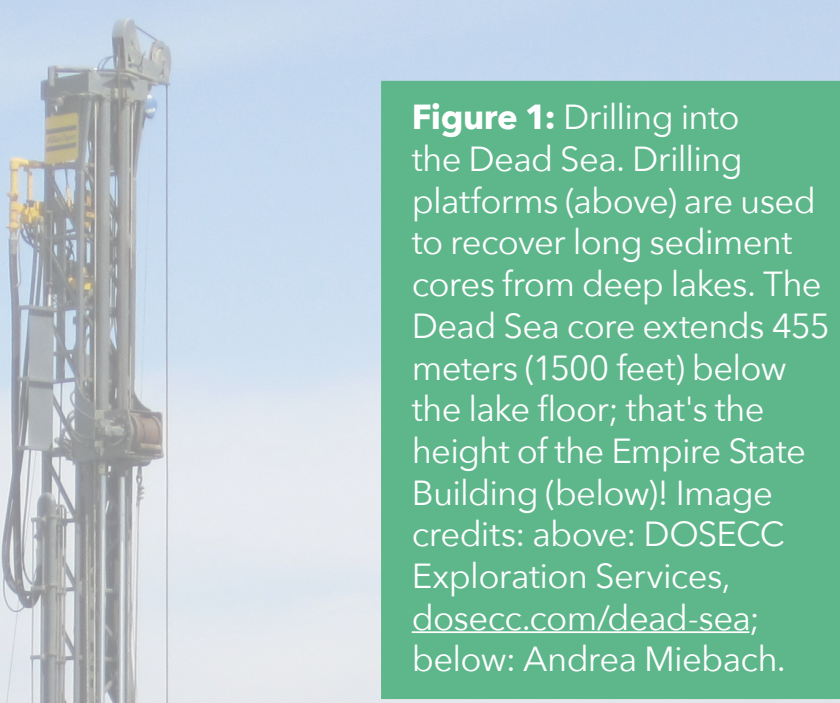

\section{Drilling into the history}

A team of researchers and technicians is working on a platform that is floating on the Dead Sea. Below them are 300 meters (1000 feet) of salty water and tons of sediment (Fig. 1). The sediment is the mud at the bottom of the lake. Lake? Yes, the Dead Sea is actually not a sea but a deep and very salty lake in the Middle East. The international team is drilling into the lake floor to recover a sediment core. The deeper they drill, the older the sediment is. This is a tough task because the sediment is not only made of soft clay and organic material but also of salt that's hard as rock (Fig. 4). In addition, the sediment covers particles that are hardly detectable with the naked eye: pollen. That's one reason that they drill into the lake floor: they want to find pollen that was continuously trapped and preserved in the lake because it tells what the surrounding landscape looked like thousands of years ago.

How does pollen reach the lake? Pollen is almost everywhere. Plants produce millions of pollen grains in order to reproduce. Since plants can't move, they have found ways for pollen to be transported from one flower to another. Wind is a powerful assistant, as it can blow the small grains into the air. However, only a few pollen grains find the appropriate plant for reproduction - most pollen grains are scattered across the landscape. The majority of these grains eventually get destroyed. However, luckily for us, some grains are trapped in a suitable setting, such as the bottom of a lake, where they are preserved for hundreds, thousands, or even millions of years.
The Dead Sea drilling team is successful and recovers a 455 meter-long (1500 feet) sediment core - one of the longest lake cores in the world. Now the analyses can begin.

\section{Let's take a look through the microscope}

Their mission is clear: the researchers want to find pollen grains in the Dead Sea sediments. However, if you were to look at the mud cores - even through a

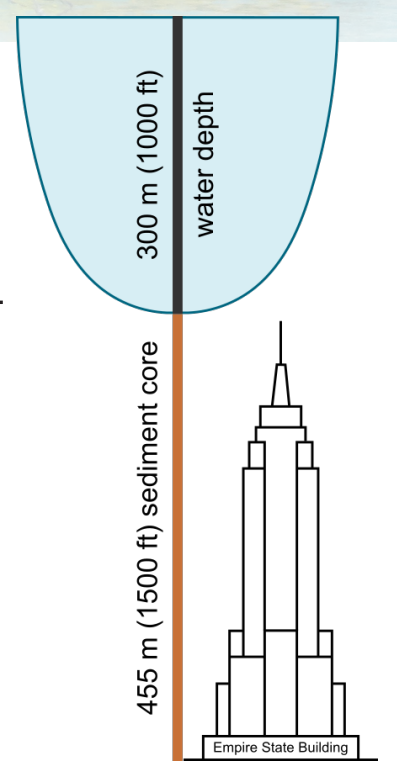
microscope - you would hardly see any pollen. First, you would have to get rid of the remaining sediment, which is done with the help of chemicals and very fine sieves. The final pollen samples would comprise hundreds of pollen grains and only a few other sediment components. Pollen grains have a robust wall that protects them from the chemical treatment and allows them to survive for millions of years. The grains differ in size, shape, and surface structure (Fig. 2). Furthermore, the grains from different pollen types have characteristic pores and furrows. This is where the pollen tube grows out of the grain, allowing the plant to reproduce. Most importantly, these features are specific for certain plants, which allows us to identify the parent plant that produced the pollen. 
Figure 2: This is a small selection of pollen types with their parent plants representing the main kinds of vegetation of the Dead Sea area. See how small (scale = only one-tenth of the width of a human hair), diverse, and beautiful the world of pollen is? Fun fact: these pollen grains from the Dead Sea are 77,000 years old but look just like modern ones. Image credit: Andrea Miebach.

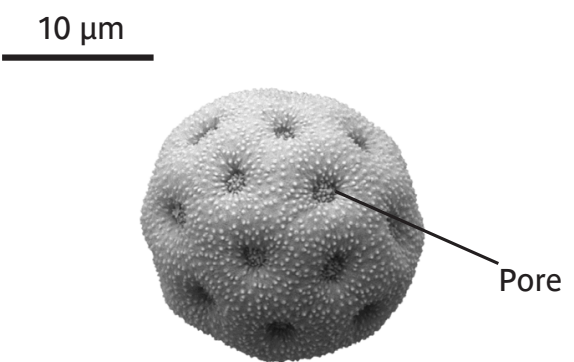

Amaranth family a typical desert plant family

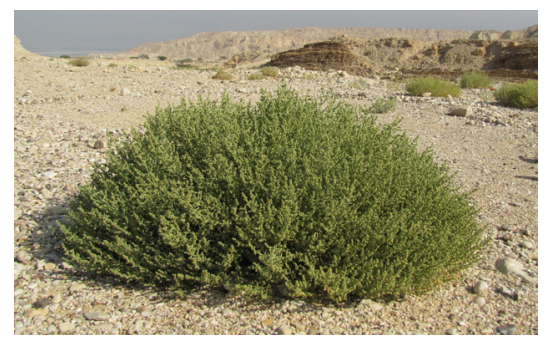

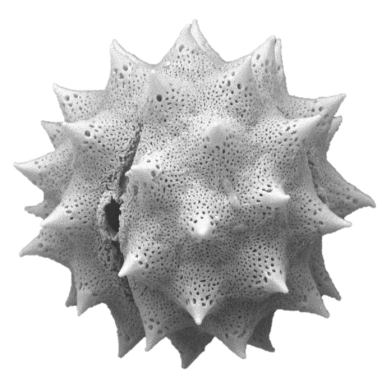

Composite a typical steppe herb

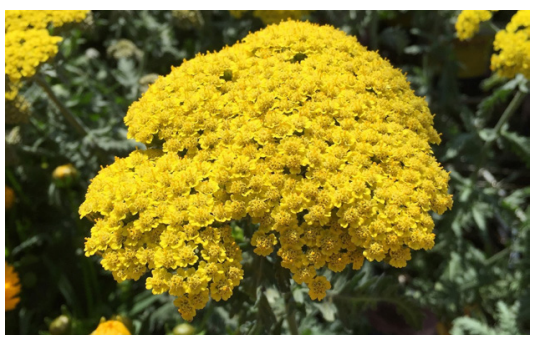

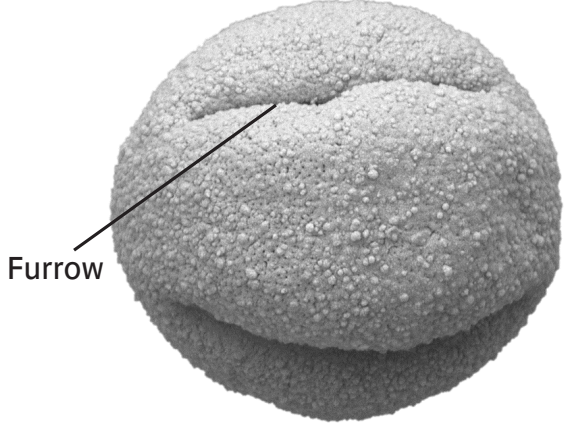

Oak a typical forest tree

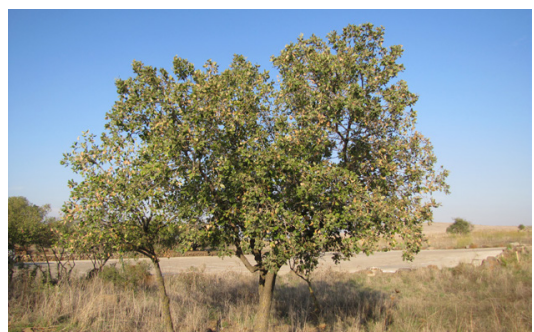

Figure 3: With the help of pollen, we can infer the ancient vegetation surrounding the Dead Sea (top). Moreover, we can reconstruct climate, for instance annual rainfall (bottom). The stronger the blue color, the more likely it is that the amount of rain was somewhere in this range. Figure adapted from Litt et al. ${ }^{1}$
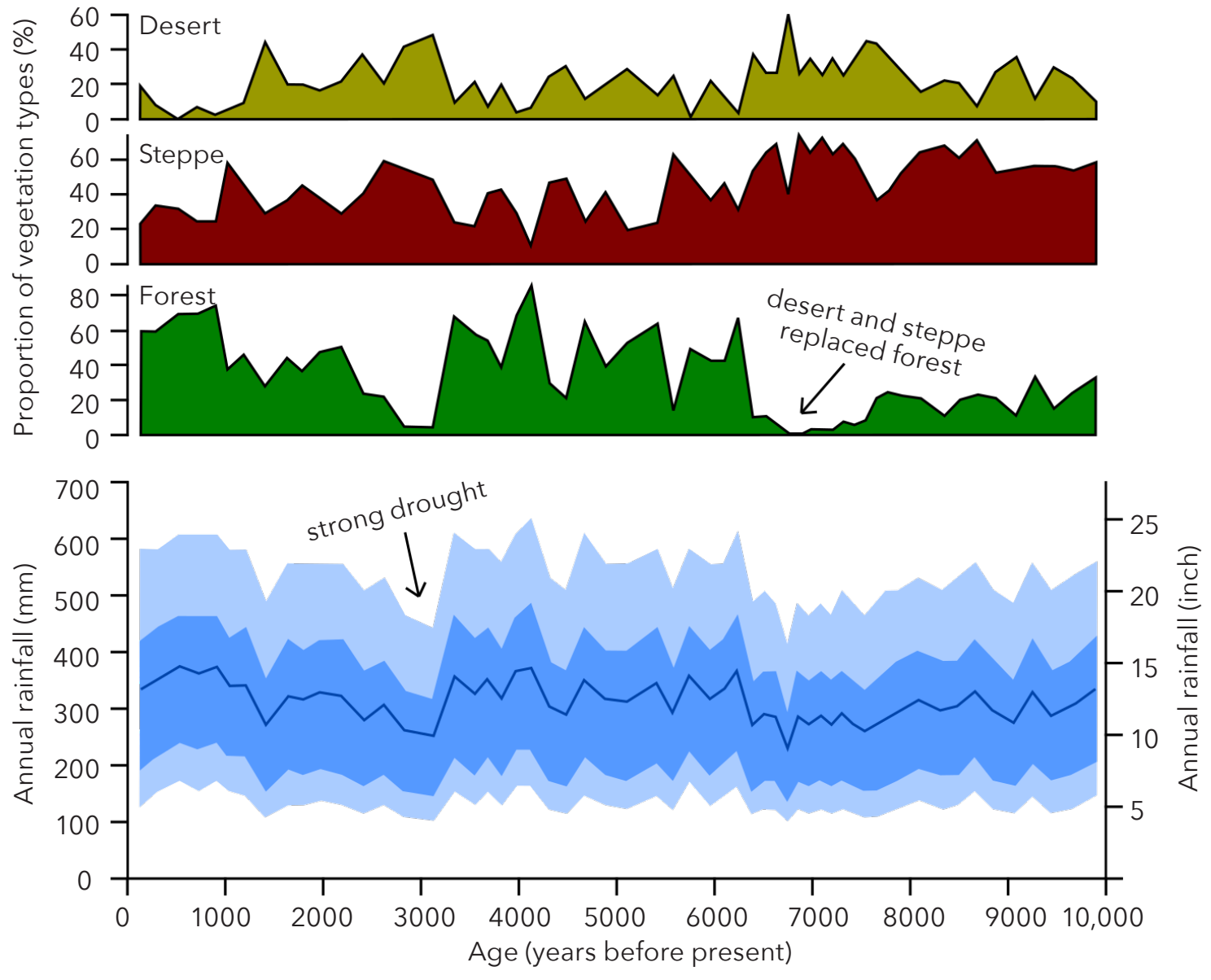
Learning from the past to better understand current climate change

The team of scientists is excited. After spending weeks in the lab and countless hours at the microscope, they have finished the pollen identification and counting. Now it's time to reconstruct the vegetation and the climate of the past. But how? The principle is easy: the analyzed pollen grains were produced by plants surrounding the lake; thus, they allow us to figure out what kind of vegetation was formerly found in this region. Since every plant is adapted to a certain climate, the ancient climate can be reconstructed as well.

Let's have a look at the Dead Sea. Today, the lake is surrounded by forested mountains, and the tree pollen is blown into the lake. However, there were also times in history when almost no tree pollen reached the Dead Sea. Desert and steppe were widespread during these phases, replacing the forest (Fig. 3 top). Think of a landscape with little vegetation, comprised of shrubs, herbs, and grasses. These periods must have been drier than today because grasses and herbs need less water than trees to survive. Even past rainfall can be calculated if complex statistics are used (Fig. 3 bottom). Analyzing the entire sediment sequence, the scientists can infer the vegetation and climate history of the region and relate this to human history. For example, the strong drought about 3000 years ago that is indicated in the Dead Sea record in Figure 3 most likely played an important role in the end of Bronze Age civilizations of Middle Eastern societies.

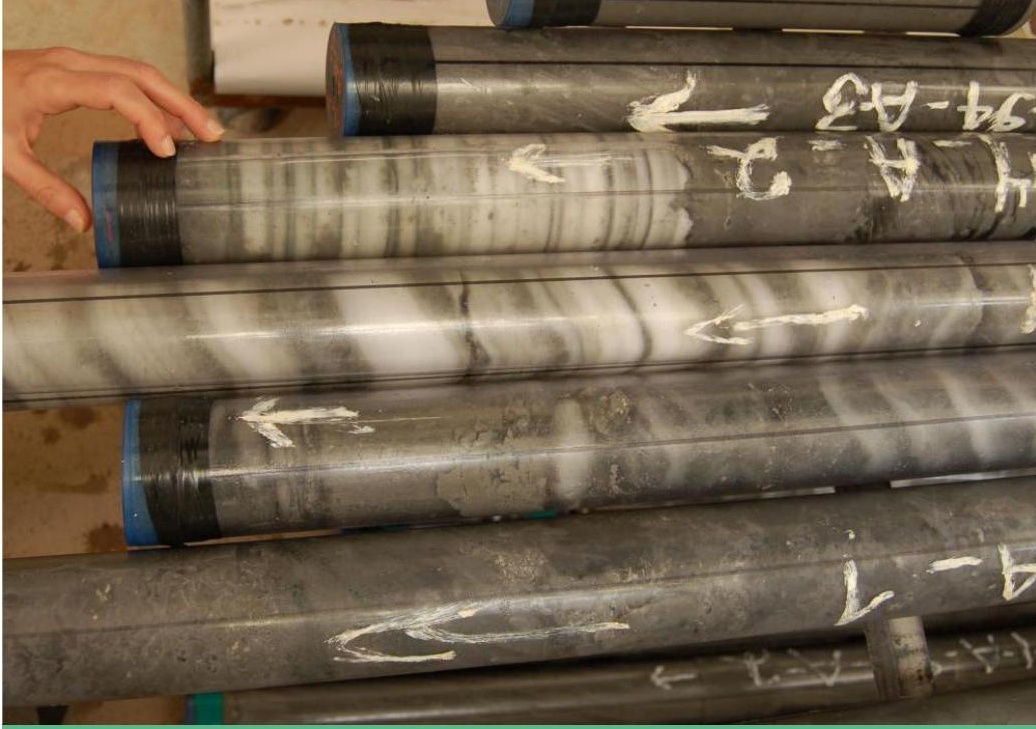

Figure 4: The variety of sediments reflect the varied environments of the past. Sediments are comprised of different components including pollen grains. Image credit: ICDP Office 2020, GFZ German Research Centre for Geosciences, icdp-online.org/projects/world/asia/dead-seaisrael/details

This knowledge helps us to evaluate recent and future changes in climate. Instrumental weather records from weather stations are limited to the last few centuries. With the help of pollen and other climate indicators of long sediment cores, we can detect climate changes over a much longer period. We can learn how fast climate was changing under natural conditions and how shifts in climate influenced ecosystems. These insights help us predict how our planet will react to the ongoing climate change.

\section{POLLEN REVEALS THE PLANT WORLD OF THE PAST}

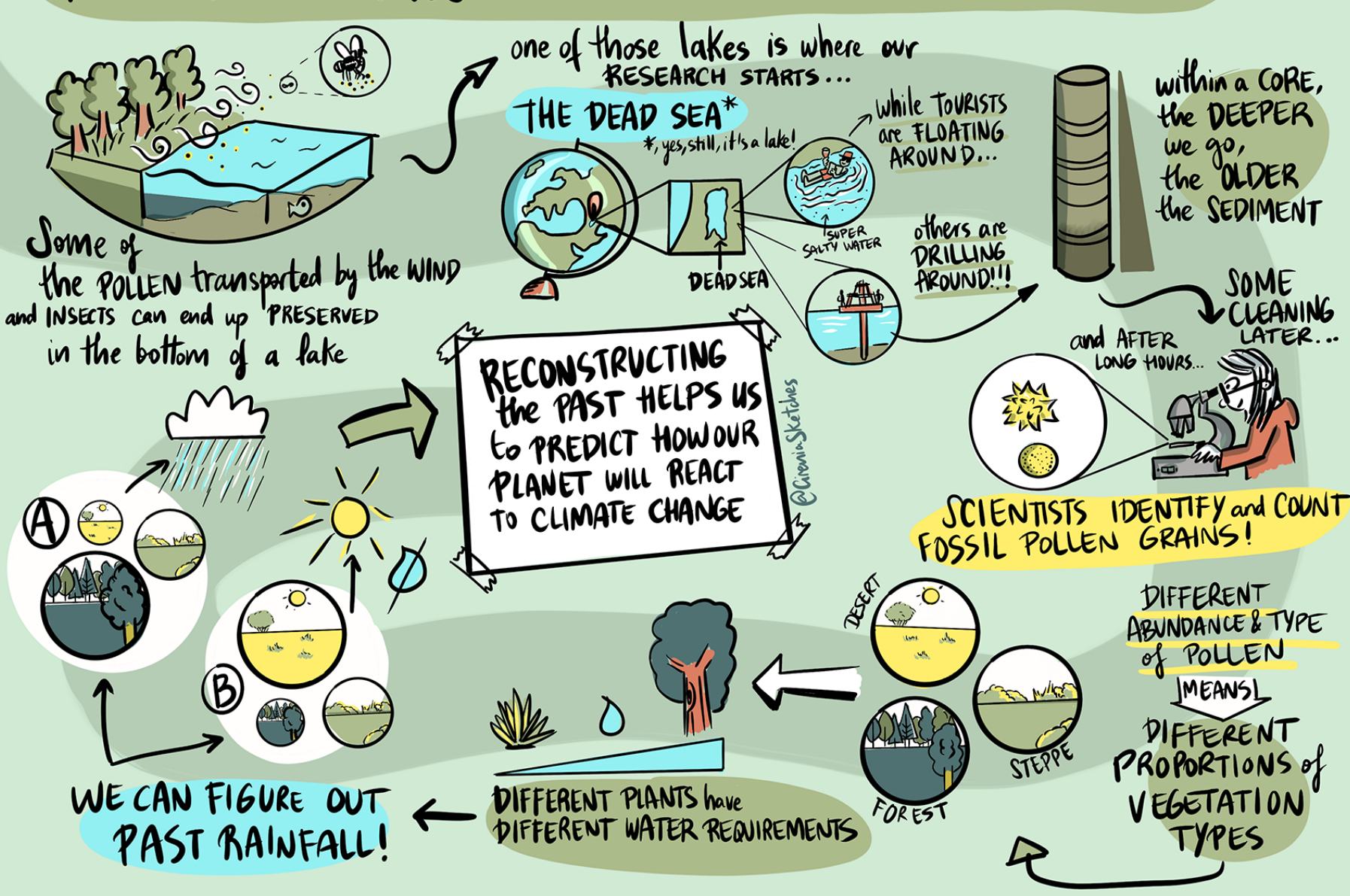

